\title{
Social media and spreading panic among adults during the COVID-19 pandemic, Egypt
}

\author{
Walaa M. Shehata ${ }^{1}$. Doaa E. Abdeldaim ${ }^{1}$
}

Received: 6 September 2021 / Accepted: 13 November 2021 / Published online: 22 November 2021

(c) The Author(s), under exclusive licence to Springer-Verlag GmbH Germany, part of Springer Nature 2021

\begin{abstract}
The COVID-19 pandemic became a challenge to human well-being. The rapid spread of the coronavirus diseases with quarantine measures make people use social media platforms more than before. The bad use of social media platforms affects the mental health of users leading to spread of panic among persons. This study aimed to determine the impact of social media on spreading panic about COVID-19 among adults in Egypt. This was a cross-sectional study that enrolled 2032 participants through online snowball sampling approach conducted during May 2021 to collect data from adults in Egypt. A self-administered questionnaire was used. It consists of three sections as follows: demographic characteristics, the social media platforms employed during the pandemic, the impact of social media on study participants. Nearly half of both sexes believed that spreading news about COVID-19 on social media platforms has a major role in spreading fear among people. More than half of the study participants reported that the level of Egyptian pages on social media covering COVID-19 was not good. A total of $46 \%$ females and $30.1 \%$ of males; those with primary, preparatory, higher, and postgraduate education; and $46.7 \%$ of medical and $32.1 \%$ of nonmedical were psychologically affected. The impact of social media on spreading panic among Egyptians varies according to gender, level of education, and occupation. Therefore, social media played an important role in spreading panic during the COVID-19 pandemic.
\end{abstract}

Keywords Social media $\cdot$ Panic $\cdot$ Adults $\cdot$ COVID-19 $\cdot$ Pandemic $\cdot$ Egypt

\section{Introduction}

COVID-19 (the coronavirus disease) is a respiratory tract illness caused by severe acute respiratory syndrome coronavirus 2 (SARS-CoV-2). In December 2019, COVID-19 first cases appeared in Wuhan, China (Lai et al. 2020). On the 11th of March 2020 and after affecting about 114 countries, the World Health Organization (WHO) declared that this COVID-19 outbreak is a global pandemic which in turn

Responsible Editor: Lotfi Aleya

I have not submitted my manuscript to a preprint server before submitting it to Environmental Science and Pollution Research.

Doaa E. Abdeldaim

Doaam3y@gmail.com

Walaa M. Shehata

princesswalaa2008@yahoo.com

1 Public Health and Community Medicine Department, Faculty of Medicine, Tanta University, Tanta, Egypt activated the state of emergency all over the world (Shigemura et al. 2020). The COVID-19 pandemic led to a state of panic and anxiety worldwide. This panic was attributed to the rapid increase in number of COVID-19 cases and deaths and the uncertainty about its complications, outcome, and treatment (Jiloha 2020).

In Egypt, since February 2020 when the first case of COVID-19 was reported, a rapid increase of cases had occurred to reach about 258,407 confirmed cases and 14,904 deaths as reported by the WHO in May 2021 (WHO 2021). The COVID-19 pandemic led to significant health, social, economic, and environmental challenges to the world (Radwan et al. 2020), and in response to it, strict preventative measures were taken by countries in the form of lockdown and the closure of all workplaces, schools, shops, and governmental institutions (Brooks et al. 2020). These prolonged and strict quarantine measures, social isolation, and economic deterioration make media play an important role in increasing panic and psychological distress especially among females (Brooks et al. 2020; Lahav 2020). 
For the first time in the human history, it becomes possible to communicate during a pandemic, and social media platforms became the main source for getting and disseminating information (Gonzalez-Padilla and Tortolero-Blanco 2020). This made the WHO declared that they have to fight not only the COVID-19 pandemic but they also have to fight what's called social media infodemic, due to rapid dissemination of information and misinformation around the world which was the main cause of feeling panic, fear, and anxiety among people (Ahmad and Murad 2020).

From the beginning of the lockdown, the usage of social media has been increased by $87 \%$ (Anwar et al. 2020). The easy and inexpensive access to social media platforms and the presence of a large number of users make these platforms the fastest and the easiest way to disseminate information during the COVID-19 pandemic (Radwan et al. 2020). During periods of crisis, uncertainty and anxiety about current events increases, and people try to calm their doubts, relieve their anxieties, and understand the situation better through social media (Hossain et al. 2020). Because people did not know enough information about COVID-19, they depend on using social media to get information, and also they start to share information, photos, and videos whatever they are true or false (Lwin et al. 2020; Zhao et al. 2020).

Both positive and negative roles had been played by these platforms during the COVID-19 crisis. Good and reasonable use of these platforms helps to disseminate recent information and scientific findings quickly, share new diagnostic tools and treatment protocols, and compare them globally with removal of the geographical boundaries between countries (Gonzalez-Padilla and Tortolero-Blanco 2020). Social media platforms also played a positive role in maintaining communication between people by interacting with each other through social media sites (like Facebook, Twitter, and WhatsApp) to reduce the negative psychological effect of social isolation with associated anxiety and stress (Brooks et al. 2020).

On the other hand, social media played a negative and harmful role from the beginning of the COVID-19 crisis by disseminating wrong rumors and conspiracy theories related to the origin of the virus (Torales et al. 2020). Social media platforms increase the spread of rumors and misleading information which are presented by fearful persons looking for a feeling of security as facts (Cinelli et al. 2020).

Dissemination of fake information through social media may cause mental health problems, as family problems, poor personal relationships, social isolation, anxiety, panic attacks, depression, and behavioral problems (Li et al. 2020; Zheng et al. 2020). The negative effects of fake news on the mental health of individuals coupled with stress and fear of quarantine, lockdown, and social isolation accentuated their panic, anxiety, depression, phobia, etc. (Kumari
2021). It was found that the spread of panic and anxiety during the COVID-19 pandemic was faster than the virus itself (Muwahed 2020). This state of panic across the world not only affected the mental health of people but also led to excessive storage of goods, food, sanitizers, and facial masks which cause their shortage across the world (Torales et al. 2020). So, our study is an alarm to health authorities to remove misinformation and create formal accounts on social media platforms to provide people with correct and trusted information during the COVID-19 pandemic and minimize their panic.

The aim of the present study is to determine the impact of social media on spreading panic about COVID-19 among adults in Egypt.

\section{Subjects and methods}

\section{Study design}

This is a cross-sectional study.

\section{Target population and sampling}

The study was conducted over a period of 1 month during May 2021. The target population was Egyptian people who reside in Egypt and aged $\geq 18$ years old. Participants were recruited using a convenience sampling technique, reached through the authors' networks and social media platforms due to the current situation of imposed physical distancing as a result of the COVID-19 pandemic.

The study participants were recruited using the snowball nonrandom sampling technique to collect data from participants. The link of the survey was sent by the authors to many various websites and social networks. The respondents were kindly asked to share the survey link with their contacts. Therefore the questionnaire was rolled out with many participants rather than the initial recipients. The total sample size was 2032 participants. A pilot study was carried out to determine the feasibility of the questionnaire before conducting the study.

\section{Study tool}

A self-administered structured questionnaire developed by Ahmad and Murad was used in this study (Ahmad and Murad 2020). The questionnaire consisted of three parts: the first part included items on sociodemographic factors (age, gender, marital status, education, residence, education and occupation). The second part was about the social media platforms used to get information about COVID-19 during the pandemic. The third part was about the impact of social 
media on spreading panic among study participants during the COVID-19 pandemic, and the response to some questions was yes, no, and neutral. This was a valid and reliable questionnaire (Cronbach's Alpha 0.89).

\section{Statistical analysis}

Statistical Package for Social Sciences (SPSS IBM Chicago, version 23) was used to analyze data of the study. Descriptive presentations were done for all variables of the study and relation between groups was done by using chi square test. Level of significance was at $p<0.05$.

\section{Results}

Sociodemographic data of the study participant is shown in Table 1. The mean age of participants was 33 years, and more than three quarters were females $(85.6 \%)$. In total, $72.4 \%$ were married, $76 \%$ were from urban areas, $57.5 \%$ were postgraduate, and $79.7 \%$ worked in the medical field. Table 2 shows the social media platforms used to get news about COVID-19. The results showed that most responders (92.1\%) used Facebook to obtain more information about COVID-19 and followed mixed news and health news $(57.7 \%, 29.1 \%)$, respectively, on social media. Table 3 discusses the relation between participants' gender

Table 1 Sociodemographic data of the studied participants

\begin{tabular}{ll}
\hline Sociodemographic data & Mean \pm SD \\
\hline Age & $33 \pm 8.2$ \\
Sex & \\
Male & $292(14.4 \%)$ \\
Female & $1740(85.6 \%)$ \\
Marital status: & \\
Single & $500(24.6 \%)$ \\
Married & $1472(72.4 \%)$ \\
Divorced & $52(2.6 \%)$ \\
Widow & $8(0.4 \%)$ \\
Residence & \\
Rural & $488(24 \%)$ \\
Urban & $1544(76 \%)$ \\
Education & \\
Primary and preparatory & $12(0.6 \%)$ \\
Secondary and diploma & $84(4.1 \%)$ \\
University & $768(37.8 \%)$ \\
Postgraduate & $1168(57.5 \%)$ \\
Occupation & \\
Medical & $1620(79.7 \%)$ \\
Nonmedical & $224(11 \%)$ \\
Housewife or no work & $188(9.3 \%)$ \\
\hline
\end{tabular}

Table 2 The social media platforms used to get news about COVID19 and news topics

\begin{tabular}{ll}
\hline Social media platforms & Frequency $(\%)$ \\
\hline Facebook & $1872(92.1 \%)$ \\
Instagram & $24(1.2 \%)$ \\
Twitter & $32(1.6 \%)$ \\
YouTube & $28(1.4 \%)$ \\
WhatsApp & $72(3.5 \%)$ \\
Telegram & $4(0.2 \%)$ \\
News topics: & \\
Social news & $176(8.7 \%)$ \\
Health news (COVID-19) & $592(29.1 \%)$ \\
Technology news & $8(0.4 \%)$ \\
Economic news & $24(1.2 \%)$ \\
Sport news & $40(2 \%)$ \\
Political news & $20(1 \%)$ \\
Mixed news & $1172(57.7 \%)$ \\
\hline
\end{tabular}

and the effect of social media in spreading panic about COVID-19. More than half of males (54.8\%) and $47.8 \%$ of females thought that publishing news related to COVID19 on social media has spread fear among people. More than half of the study participants (59.8\% of females and $50.7 \%$ of males) believed that the level of Egyptian pages and groups on social media covering COVID-19 was not good. A total of $52.2 \%$ of males and $53.3 \%$ of females did not publish any news about COVID-19 on social media. More than three quarters of both sexes $(80.8 \%$ and $85.1 \%$ of males and females, respectively) agreed with the importance of filters and a specific policy to be set up for social media during the pandemic. Nearly one third of males and females thought that dissemination of the number of cases and deaths of COVID-19 created panic on social media. Regarding panic caused by social media about COVID-19, $46 \%$ of females were psychologically affected, while $39.7 \%$ of males had no fear. Table 4 illustrates the impact of panic caused by social media in relation to participants' level of education. The majority of participants whatever their level of education thought that publishing news about COVID-19 on social media spread fear and panic among the people. As regards the level of covering of Egyptian pages, more than half of primary, preparatory, secondary, and diploma participants thought that social media covered COVID-19 well, while most of high educated and postgraduate participants found this coverage is bad. A total of $66.7 \%$ of primary and preparatory educated participants published news about COVID-19 on social media, but higher percentage of secondary, higher educated, and postgraduate participants did not publish any information. Nearly all participants needed filters to be set up for social media. Higher percentage of 
Table 3 Responses of some questions about COVID-19 respecting the gender of study participants

\begin{tabular}{|c|c|c|c|}
\hline \multirow[t]{2}{*}{ Variable } & \multicolumn{3}{|l|}{ Gender } \\
\hline & Male $(n=292)$ & Female $(n=1740)$ & $P$ value \\
\hline $\begin{array}{l}\text { Do you think that publishing more news related to COVID-19 on social media has spread fear } \\
\text { and panic among the people? }\end{array}$ & & & $0.000^{*}$ \\
\hline Yes & $160(54.8 \%)$ & $832(47.8 \%)$ & \\
\hline No & $96(32.9 \%)$ & $444(25.5 \%)$ & \\
\hline Neutral & $36(12.3 \%)$ & $464(26.7 \%)$ & \\
\hline $\begin{array}{l}\text { Do you think the level of Egyptian pages, groups, and accounts on social media covering } \\
\text { COVID-19 is good? }\end{array}$ & & & $0.000^{*}$ \\
\hline Yes & $80(27.4 \%)$ & $300(17.2 \%)$ & \\
\hline No & $148(50.7 \%)$ & $1040(59.8 \%)$ & \\
\hline Neutral & $64(21.9 \%)$ & $400(23 \%)$ & \\
\hline Have you published any information and news related to COVID-19 on social media? & & & 0.9 \\
\hline Yes & $119(40.9 \%)$ & $696(40 \%)$ & \\
\hline No & $152(52.2 \%)$ & $928(53.3 \%)$ & \\
\hline Neutral & & $116(60 \%)$ & \\
\hline $\begin{array}{l}\text { Do filters need to be set up for social media and a specific policy followed during humanitar- } \\
\text { ian crises such as the spread of COVID-19? }\end{array}$ & $20(0.910)$ & $110(0.970)$ & $0.03 *$ \\
\hline Yes & $236(80.8 \%)$ & $1480(85.1 \%)$ & \\
\hline No & $32(11 \%)$ & $116(6.7 \%)$ & \\
\hline Neutral & $24(8.2 \%)$ & $144(8.3 \%)$ & \\
\hline Type of information related to COVID-19 that create panic on social media & & & $0.000 *$ \\
\hline Dissemination of the number of COVID-19 infections & $24(8.2 \%)$ & $68(3.9 \%)$ & \\
\hline Dissemination of the death toll & $32(11 \%)$ & $308(17.7 \%)$ & \\
\hline Dissemination of the number of cases and deaths & $104(35.6 \%)$ & $588(33.8 \%)$ & \\
\hline Dissemination of panic including information of COVID-19 & $44(15.1 \%)$ & $364(20.9 \%)$ & \\
\hline Posting of videos, photos, and news of the countries with a high number of cases & $52(17.8 \%)$ & $176(10.1 \%)$ & \\
\hline Fake news about the COVID-19 outbreak & $28(9.6 \%)$ & $120(6.9 \%)$ & \\
\hline Others & $8(2.7 \%)$ & $116(6.7 \%)$ & \\
\hline The impact of panic resulting from social media about COVID-19 & & & $0.000 *$ \\
\hline Psychological & $88(30.1 \%)$ & $800(46 \%)$ & \\
\hline Physical & $4(1.4 \%)$ & $4(0.2 \%)$ & \\
\hline Psychophysical & $32(11 \%)$ & $232(13.3 \%)$ & \\
\hline All of the above & $52(17.8 \%)$ & $340(19.5 \%)$ & \\
\hline No fear & $116(39.7 \%)$ & $364(20.9 \%)$ & \\
\hline
\end{tabular}

participants agreed that dissemination of number of deaths and cases of COVID-19 created panic on social media. The impact of panic differs among participants with different levels of education. The higher percentage of participants who suffered from psychological impact of social media were those with primary, preparatory, higher, and postgraduate education, while half of the participants $(52.4 \%)$ who had secondary education had no fear. Table 5 discusses the impact of panic caused by social media about COVID-19 in relation with participants' occupation. A total of $49.9 \%$, $42.9 \%$, and $46.8 \%$ of medical, nonmedical, and housewives/ no work participants, respectively, agreed that publishing news related to COVID-19 on social media spread panic among people. In total, $60.5 \%$ and $62.5 \%$ of medical and nonmedical participants thought that Egyptian pages covering on social media is bad, while $42.6 \%$ of housewives/no work had neutral opinion. More than half of participants in three categories of occupation did not publish any information about COVID-19. More than three quarters of participants whatever their occupation believed that filters are needed to set up for social media during spread of COVID19. Dissemination of the number of cases and deaths about COVID-19 created panic among the majority of participants regardless of their occupation $(31.9 \%$ medical, $44.6 \%$ nonmedical, $40.4 \%$ housewives/no work). Among the medical and nonmedical participants, $46.7 \%$ and $32.1 \%$, respectively, had psychological symptoms resulting from panic of social media. On the other hand, $32.1 \%$ and $34 \%$ in nonmedical and 
Table 4 Responses of some questions about COVID-19 respecting the education of study participants

\begin{tabular}{|c|c|c|c|c|c|}
\hline \multirow[t]{2}{*}{ Variable } & \multicolumn{4}{|l|}{ Education } & \multirow[t]{2}{*}{$P$ value } \\
\hline & Prim and prep & $\begin{array}{l}\text { Second- } \\
\text { ary and } \\
\text { diploma }\end{array}$ & High & Post & \\
\hline $\begin{array}{l}\text { Do you think that publishing more news related to COVID-19 on social } \\
\text { media has spread fear and panic among the people? }\end{array}$ & & & & & $0.03 *$ \\
\hline Yes & $8(66.7 \%)$ & $40(47.6 \%)$ & $348(45.3 \%)$ & $596(51 \%)$ & \\
\hline No & $0(0 \%)$ & $24(28.6 \%)$ & $204(26.6 \%)$ & $312(26.7 \%)$ & \\
\hline Neutral & $4(33.3 \%)$ & $20(23.8 \%)$ & $216(28.1 \%)$ & $260(22.3 \%)$ & \\
\hline $\begin{array}{l}\text { Do you think the level of Egyptian pages, groups, and accounts on social } \\
\text { media covering COVID-19 is good? }\end{array}$ & & & & & $0.000 *$ \\
\hline Yes & $8(66.7 \%)$ & $44(52.4 \%)$ & $140(18.2 \%)$ & $188(16.1 \%)$ & \\
\hline No & $0(0 \%)$ & $16(19 \%)$ & $436(56.8 \%)$ & $736(63 \%)$ & \\
\hline Neutral & $4(33.3 \%)$ & $24(28.6 \%)$ & $192(25 \%)$ & $244(20.9 \%)$ & \\
\hline $\begin{array}{l}\text { Have you published any information and news related to COVID-19 on } \\
\text { social media? }\end{array}$ & & & & & 0.06 \\
\hline Yes & $8(66.7 \%)$ & $32(38.1 \%)$ & $279(36.4 \%)$ & $496(42.5 \%)$ & \\
\hline No & $4(33.3 \%)$ & $48(57.1 \%)$ & $436(56.8 \%)$ & $592(50.7 \%)$ & \\
\hline Neutral & $0(0 \%)$ & $4(4.8 \%)$ & $52(6.8 \%)$ & $80(6.8 \%)$ & \\
\hline \multicolumn{6}{|l|}{$\begin{array}{l}\text { Do filters need to be set up for social media and a specific policy followed } \\
\text { during humanitarian crises such as the spread of COVID-19? }\end{array}$} \\
\hline Yes & $12(100 \%)$ & $76(90.5 \%)$ & $672(87.5 \%)$ & $956(81.8 \%)$ & $0.000^{*}$ \\
\hline No & $0(0 \%)$ & $0(0 \%)$ & $32(4.2 \%)$ & $116(9.9 \%)$ & \\
\hline Neutral & $0(0 \%)$ & $8(9.5 \%)$ & $64(8.3 \%)$ & $96(8.2 \%)$ & \\
\hline $\begin{array}{l}\text { Type of information related to COVID-19 that create panic on social } \\
\text { media }\end{array}$ & & & & & $0.000 *$ \\
\hline Dissemination of the number of COVID-19 infections & $4(33.3 \%)$ & $4(4.8 \%)$ & $40(5.2 \%)$ & $44(3.8 \%)$ & \\
\hline Dissemination of the death toll & $0(0 \%)$ & $8(9.5 \%)$ & $100(13 \%)$ & $232(19.9 \%)$ & \\
\hline Dissemination of the number of cases and deaths & $8(66.7 \%)$ & $48(57.1 \%)$ & $252(32.8 \%)$ & $384(32.9 \%)$ & \\
\hline Dissemination of panic including information of COVID-19 & $0(0 \%)$ & $4(4.8 \%)$ & $204(26.6 \%)$ & $200(17.1 \%)$ & \\
\hline $\begin{array}{l}\text { Posting of videos, photos, and news of the countries with a high number of } \\
\text { cases }\end{array}$ & $0(0 \%)$ & $4(4.8 \%)$ & $84(10.9 \%)$ & $140(12 \%)$ & \\
\hline Fake news about the COVID-19 outbreak & $0(0 \%)$ & $12(14.3 \%)$ & $56(7.3 \%)$ & $80(6.8 \%)$ & \\
\hline Others & $0(0 \%)$ & $4(4.8 \%)$ & $32(4.2 \%)$ & $88(7.5 \%)$ & \\
\hline The impact of panic resulting from social media about COVID-19 & & & & & $0.000^{*}$ \\
\hline Psychological & $12(100 \%)$ & $8(9.5 \%)$ & $352(45.8 \%)$ & $516(44.2 \%)$ & \\
\hline Physical & $0(0 \%)$ & $0(0 \%)$ & $8(1 \%)$ & $0(0 \%)$ & \\
\hline Psychophysical & $0(0 \%)$ & $4(4.8 \%)$ & $100(13 \%)$ & $160(13.7 \%)$ & \\
\hline All of the above & $0(0 \%)$ & $28(33.3 \%)$ & $140(18.2 \%)$ & $224(19.2 \%)$ & \\
\hline No fear & $0(0 \%)$ & $44(52.4 \%)$ & $168(21.9 \%)$ & $268(22.9 \%)$ & \\
\hline
\end{tabular}

housewives/no work groups, respectively, had no fear from COVID-19 news on social media.

\section{Discussion}

The COVID-19 pandemic became a big challenge to the human survival and well-being. Although social media is one of the main channels to get information about COVID19 , it also amplifies this challenge by disseminating false information through social media platforms which increases the spread of panic and anxiety among people during the epidemic (Hammad and Alqarni 2021).

The current study showed that most of our included Egyptian adults (92.1\%) got more information about COVID-19 from Facebook, while Telegram, Instagram, Twitter, and YouTube were found the least used platforms for getting news and information. This can be explained as Facebook is the most popular social media platform used in Egypt. This is in accordance with the results of Ahmad and Murad 
Table 5 Responses of some questions about COVID-19 respecting the occupation of study participants

\begin{tabular}{|c|c|c|c|c|}
\hline \multirow[t]{2}{*}{ Variable } & \multicolumn{3}{|l|}{ Occupation } & \multirow[t]{2}{*}{$P$ value } \\
\hline & Medical & Nonmedical & Housewife/no work & \\
\hline $\begin{array}{l}\text { Do you think that publishing more news related to COVID-19 on social media } \\
\text { has spread fear and panic among the people? }\end{array}$ & & & & 0.3 \\
\hline Yes & $808(49.9 \%)$ & $96(42.9 \%)$ & $88(46.8 \%)$ & \\
\hline No & $424(26.2 \%)$ & $68(30.4 \%)$ & $48(25.5 \%)$ & \\
\hline Neutral & $388(24 \%)$ & $60(26.8 \%)$ & $52(27.7 \%)$ & \\
\hline $\begin{array}{l}\text { Do you think the level of Egyptian pages, groups, and accounts on social media } \\
\text { covering COVID-19 is good? }\end{array}$ & & & & $0.000 *$ \\
\hline Yes & $300(18.5 \%)$ & $40(17.9 \%)$ & $40(21.3 \%)$ & \\
\hline No & $980(60.5 \%)$ & $140(62.5 \%)$ & $68(36.2 \%)$ & \\
\hline Neutral & $340(21 \%)$ & $44(19.6 \%)$ & $80(42.6 \%)$ & \\
\hline $\begin{array}{l}\text { Have you published any information and news related to COVID-19 on social } \\
\text { media? }\end{array}$ & & & & $0.000 *$ \\
\hline Yes & $692(42.7 \%)$ & $80(35.7 \%)$ & $43(23 \%)$ & \\
\hline No & $824(50.9 \%)$ & $132(58.9 \%)$ & $124(66.3 \%)$ & \\
\hline Neutral & $104(6.4 \%)$ & $12(5.4 \%)$ & $20(10.7 \%)$ & \\
\hline $\begin{array}{l}\text { Do filters need to be set up for social media and a specific policy followed dur- } \\
\text { ing humanitarian crises such as the spread of the COVID-19? }\end{array}$ & & & & $0.000 *$ \\
\hline Yes & $1376(84.9 \%)$ & $192(85.7 \%)$ & $148(78.7 \%)$ & \\
\hline No & $132(8.1 \%)$ & $8(3.6 \%)$ & $8(4.3 \%)$ & \\
\hline Neutral & $112(6.9 \%)$ & $24(10.7 \%)$ & $32(17 \%)$ & \\
\hline Type of information related to COVID-19 that create panic on social media & & & & $0.000 *$ \\
\hline Dissemination of the number of COVID-19 infections & $80(4.9)$ & $4(1.8 \%)$ & $8(4.3 \%)$ & \\
\hline Dissemination of the death toll & $284(17.5 \%)$ & $24(10.7 \%)$ & $32(17 \%)$ & \\
\hline Dissemination of the number of cases and deaths & $516(31.9 \%)$ & $100(44.6 \%)$ & $76(40.4 \%)$ & \\
\hline Dissemination of panic including information of COVID-19 & $336(20.7 \%)$ & $36(16.1 \%)$ & $36(19.1 \%)$ & \\
\hline Posting of videos, photos, and news of the countries with a high number of cases & $176(10.9 \%)$ & $36(16.1 \%)$ & $16(8.5 \%)$ & \\
\hline Fake news about the COVID-19 outbreak & $112(6.9 \%)$ & $20(8.9 \%)$ & $16(8.5 \%)$ & \\
\hline Others & $116(7.2 \%)$ & $4(1.8 \%)$ & $4(2.1 \%)$ & \\
\hline The impact of panic resulting from social media about COVID-19 & & & & $0.000^{*}$ \\
\hline Psychological & $756(46.7 \%)$ & $72(32.1 \%)$ & $319(60 \%)$ & \\
\hline Physical & $8(0.5 \%)$ & $0(0 \%)$ & $0(0 \%)$ & \\
\hline Psychophysical & $200(12.3 \%)$ & $40(17.9 \%)$ & $24(12.8 \%)$ & \\
\hline All of the above & $312(19.3 \%)$ & $40(17.9 \%)$ & $40(21.3 \%)$ & \\
\hline No fear & $344(21.2 \%)$ & $72(32.1 \%)$ & $64(34 \%)$ & \\
\hline
\end{tabular}

in their study in Iraq as $82.6 \%$ of their participants were found to use Facebook to get information about COVID-19 (Ahmad and Murad 2020). Similar results were found in Palestine by Radwan et al., with $81.8 \%$ of their study participants obtained COVID-19 information by using Facebook (Radwan et al. 2020). The present study found that during COVID-19 time, $57.7 \%$ of our participants followed mixed news on social media platforms but as a separate category; health news were the most frequently followed news as it was followed by $29.1 \%$ of participants.

Similar results were revealed in other studies conducted in Palestine and Iraq. Health news were the most frequently followed news (heard, read, or seen) on social media platforms during the COVID-19 pandemic time but in a higher percentage of people than in our study as it was followed by $56.2 \%$ of Radwan et al., study participants in Palestine, and by $76.4 \%$ of Ahmad and Murad, study participants in Iraq (Radwan et al. 2020; Ahmad and Murad 2020).

On the other hand, regarding the least news followed on social media during COVID-19, it was technology news and political news in the current study but it was sports news in Radwan et al. study (Radwan et al. 2020) and the technology news in Ahmad and Murad study (Ahmad and Murad 2020).

These results revealed that the type of most followed news on social media platforms was influenced by the COVID-19 pandemic.

The results of the current study showed that nearly half of males and females with slightly higher percentage among 
males (54.8\% and $47.8 \%$, respectively) agreed with the fact that publishing news about COVID-19 on social media platforms increases the spread of fear and panic among people. This may be attributed to that males usually follow news on social media more than females and during COVID-19 pandemic more than any time before.

Higher percentage of people in other countries such as in Palestine and Iraqi Kurdistan also found that posting more news and information regarding COVID-19 on social media platforms has spread panic and fear among individuals; with $76.4 \%$ of participants in Radwan et al. study done in Gaza Strip, Palestine (Radwan et al. 2020), and 79.3\% of males and $74.8 \%$ of females in a study done in Iraqi Kurdistan by Ahmad and Murad (Ahmad and Murad 2020). Which is common in all studies is that males were supporting this idea more than females. More than half of our included Egyptian adults (59.8\% of females and $50.7 \%$ of males) believed that the level of Egyptian pages and groups on social media covering COVID-19 was not good, and only $27.4 \%$ of males and $17.2 \%$ of females found the level of covering news was good with statistically significant difference between both sexes.

Different results were found in Palestine, as a higher percentage of individuals in Radwan et al. study (46.0\%) thought that the level of Palestinian pages, groups, and accounts in covering news about COVID-19 was good but with no significant difference between both sexes (Radwan et al. 2020). Also, our results are not consistent with opinion of respondents in Iraqi Kurdistan, Iraq, with much more percentage of males and females found that the level of Iraqi Kurdish pages, groups, and accounts on covering COVID19 was good (34.9\% of males and $41 \%$ of females) (Ahmad and Murad 2020).

Regarding publishing news and information about COVID-19 on social media platforms, $40.9 \%$ of males and $40 \%$ of females included in the current study admitted that they published news about COVID-19 on social media. In Iraqi study, $51.4 \%$ of males and $58.1 \%$ of females posted information and news about COVID-19 on social media (Ahmad and Murad 2020). While in Palestine, males were found to publish information about COVID-19 on social media platforms more than females (Radwan et al. 2020).

Majority of males and females in the current study $(80.8 \%$ and $85.1 \%$, respectively) agreed with the fact that filters are needed to be put and a specific policy should be followed for social media during the COVID-19 pandemic. Similar findings were shown in Ahmad and Murad study with 79.9\% of males and $89.2 \%$ of females believed in the importance of putting filters and following special policies on using social media in pandemic times (Ahmad and Murad 2020).

Regarding what type of news regarding COVID-19 can participate in spreading panic among people; about one third of males and females in the present study thought that publishing number of cases and deaths of COVID-19 on social media causes the most panic to people. This was followed by posting of photos, videos, and news of countries with a high number of COVID-19 cases that were found to cause panic in $17.8 \%$ of males and $10.1 \%$ of females. However, publishing fake news about the COVID-19 pandemic can cause panic in only $9.6 \%$ of males and $6.9 \%$ of females.

Different findings were shown in Radwan et al. study in Palestine as the majority of their participants confirmed that disseminating the number of COVID-19 cases and publishing fake news about the COVID-19 pandemic were considered the most type of information that can cause panic about COVID-19 (Radwan et al. 2020).

Also, in a study conducted in Iraq by Ahmad and Murad, they found that publishing fake news about COVID-19 on social media causes panic in $26.6 \%$ of their participants with $17.4 \%$ of them revealed that publishing the number of COVID-19 infections participate in spreading panic among people, while only $7.6 \%$ of them reported that dissemination of the number of COVID-19 deaths can cause panic among people (Ahmad and Murad 2020).

Regarding the impact of panic caused by social media about COVID-19, the current study found that females (46\%) are psychologically affected more than males (30.1\%) as females are more likely to suffer psychological disturbances than men (Arafa et al. 2021).

On the other hand, only $20.9 \%$ of females and $39.7 \%$ of males had no fear. These results are consistent with results of a study done in Egypt by El-Zoghby et al. with $41.4 \%$ of their included Egyptian adults who were severely affected psychologically during the COVID-19 pandemic (El-Zoghby et al. 2020). Also, our results are in accordance with findings of study done by Ahmad and Murad as they found that the psychological impact was the highest impact as it affected $38.6 \%$ of their participants, while $36 \%$ of them were not afraid (Ahmad and Murad 2020).

Much more percentage of participants in Radwan et al. study (78.1\%) were psychologically affected by panic caused by social media about COVID-19, while only $1.3 \%$ of them were physically affected. This big difference may be attributed to the difference in the age groups included in these different studies (Radwan et al. 2020). Another study conducted in Egypt by Arafa et al. showed a high prevalence of depression, anxiety, and stress among Egyptian people during COVID-19 $(67.1 \%, 53.5 \%$, and $48.8 \%$, respectively) (Arafa et al. 2021).

Furthermore, a study done in Saudi Arabia revealed the presence of significant positive correlation between excessive use of social media platforms during the COVID-19 pandemic and elevated levels of depression, panic, anxiety, and social isolation among people (Hammad and Alqarni 2021). What is common among these studies is that females were psychologically affected more than males. This is 
attributed to the nature of females in general as they can be easily affected psychologically more than males.

The current study showed that the greater percentage of people who suffered psychologically by social media were those with higher education and postgraduate education. This is in accordance with the results of another study done in Egypt by Arafa et al. (Arafa et al. 2021). This can be explained as individuals with high levels of education are more concerned with COVID-19 and its consequences and follow its related news on social media than those with lower level of education, and moreover they suffered from severe to very severe anxiety, depression, and stress more than others with lower levels of education.

Different results were revealed by Gao et al. in their study as they found that the level of panic, depression, and anxiety caused by social media exposure during COVID-19 crisis was lower among individuals with university and postgraduate education than those with middle school education (Gao et al. 2020). As regards the participants' occupation, the present study found that the higher levels of psychological impact of panic caused by social media about COVID-19 were among those participants with medical occupations. This is due to the working time and labor intensity of healthcare workers which increase to face the pandemic causing them not able to have enough time to rest. So, they are exposed to chronic stress and psychological distress. These results are in contrary with results of another study in Egypt as they found that individuals who work in occupations other than the health sector suffered from higher levels of severe to very severe anxiety, depression, and stress (Arafa et al. 2021).

\section{Conclusions}

More people used social media platforms to get information and news about COVID-19. This increased the panic among people during the COVID-19 pandemic. More than half of the included Egyptian adults agreed with that publishing news about COVID-19 on social media platforms increased the spread of panic among people. The main impact of panic imposed by social media during the pandemic was psychological impact.

\section{Recommendations}

We recommend that the Egyptian government has to take legal actions in the form of imposing financial penalties and even imprisoning those who participate in publishing fake and misleading information on social media platforms. In addition, the government has to put filters on social media to delete false information and make cooperation with the
WHO to enhance the spread of accurate information to people.

Acknowledgements The authors would like to thank all participants in our study.

Author contribution The idea of this research was suggested by Walaa M. Shehata who wrote the initial protocol of this study and performed the fieldwork. Doaa E. Abdeldaim formed the statistical analysis of data. Walaa M. Shehata and Doaa E. Abdeldaim collected the data of the study, interpreted them, and wrote the manuscript. Both authors reviewed the manuscript and approved its final version.

Data availability Not applicable.

\section{Declarations}

Ethics approval and consent to participate The study was held subsequently upon approval of the Research Ethics Committee at Tanta Faculty of Medicine. A consent was attached to the Google Forms. It explained the nature of the study, objectives, and importance at the beginning of the survey link. The respondents were informed that they can withdraw from the study at any stage of the survey, and they were asked if they are fully willing to participate in this study before being enrolled. Confidentiality was assured for all participants.

Consent for publication Not applicable.

Conflict of interest The authors declare no competing interests.

\section{References}

Ahmad AR, Murad HR (2020) The impact of social media on panic during the COVID-19 pandemic in Iraqi Kurdistan: online questionnaire study. J Med Internet Res 22(5):e19556

Anwar A, Malik M, Raees V et al (2020) Role of mass media and public health communications in the COVID-19 pandemic. Cureus 12(9): 10453

Arafa A, Mohamed A, Saleh L, Senosy S (2021) Psychological impacts of the COVID-19 pandemic on the public in Egypt. Community Ment Health J 57:64-69

Brooks SK, Webster RK, Smith LE et al (2020) The psychological impact of quarantine and how to reduce it: rapid review of the evidence. Lancet. Elsevier Ltd 395:912-920

Cinelli M, Quattrociocchi W, Galeazzi A et al (2020) The Covid-19 social media infodemic. Sci Rep 10:16598

El-Zoghby SM, Soltan EM, Salama HM (2020) Impact of the COVID19 pandemic on mental health and social support among adult Egyptians. J Community Health 45(4):689-695

Gao J, Zheng P, Jia Y et al (2020) Mental health problems and social media exposure during COVID-19 outbreak. PLoS One 15(4): 0231924

Gonzalez-Padilla DA, Tortolero-Blanco L (2020) Social media influence in the COVID-19 pandemic. Int Braz J Urol 46(Suppl 1):120-124

Hammad MA, Alqarni TM (2021) Psychosocial effects of social media on the Saudi society during the coronavirus disease 2019 pandemic: a cross-sectional study. PLoS One 16(3):e0248811

Hossain MT, Ahammed B, Chanda SK et al (2020) Social and electronic media exposure and generalized anxiety disorder among 
people during COVID-19 outbreak in Bangladesh: a preliminary observation. PLoS One 15(9):e0238974

Jiloha RC (2020) COVID-19 and Mental Health. Epidem Int 5(1):7-9

Kumari A (2021) The negative impact of social media during COVID19. Psychol Educ 58(2):495-507

Lahav Y (2020) Psychological distress related to COVID-19 the contribution of continuous traumatic stress. J Affect Disord 277:129-137

Lai CC, Shih TP, Ko WC et al (2020) Severe acute respiratory syndrome coronavirus 2 (SARS-CoV-2) and coronavirus disease-2019 (COVID-19): the epidemic and the challenges, Int. J Antimicrob Agents 55(3):105924

Li S, Wang Y, Xue J et al (2020) The impact of COVID-19 epidemic declaration on psychological consequences: a study on active Weibo users. Int J Environ Res Public Health 17(6):2032

Lwin MO, Lu J, Sheldenkar A et al (2020) Global sentiments surrounding the COVID-19 pandemic on Twitter: analysis of Twitter trends, JMIR Pub. Health Surveill 6(2):e19447

Muwahed J (2020) Coronavirus pandemic goes viral in the age of social media, sparking anxiety. URL: https://tinyurl.com/ybnms 2se. Accessed 14 Mar 2020

Radwan E, Radwan A, Radwan W (2020) The role of social media in spreading panic among primary and secondary school students during the COVID-19 pandemic: an online questionnaire study from the Gaza Strip, Palestine. Heliyon 6:e05807

Shigemura J, Ursano RJ, Morganstein JC et al (2020) Public responses to the novel 2019 coronavirus (2019-nCoV) in Japan: mental health consequences and target populations. Psychiatry Clin Neurosci 74:281-282

Torales J, O'Higgins M, Castaldelli-Maia JM et al (2020) The outbreak of COVID-19 coronavirus and its impact on global mental health, Int. J Soc Psychiatr 66(4):317-320

World Health Organization (2021) WHO Health Emergency Dashboard available at https://covid19.who.int/region/emro/country/ eg. Accessed 29 May 2021

Zhao Y, Cheng S, Yu X, Xu H (2020) Chinese public's attention to the COVID-19 epidemic on social media: observational descriptive study. J Med Internet Res 22(5):e18825

Zheng Y, Goh E, Wen J (2020) The effects of misleading media reports about COVID-19 on Chinese tourists' mental health: a perspective article. Anatolia 31(2):337-340. https://doi.org/10.1080/13032 917.2020.1747208

Publisher's note Springer Nature remains neutral with regard to jurisdictional claims in published maps and institutional affiliations. 